\title{
O DIREITO DE SER SUJEITO DE DIREITOS ${ }^{1}$
}

\author{
Vania Baldi²
}

\section{RESUMO}

O presente texto tem por objetivo discutir os direitos humanos desconstruindo e reconstruindo a concepção universalística dos mesmos e observando que para tanto se faz necessário reexaminar a categoria de humano, de universal e de direito. A estratégia de articulação entre cada uma dessas categorias envolve uma constante prática de tradução histórica e cultural entre elas. Uma prática participativa, transversal e circular, apontada na direção de um ethos auto-reflexivo.

Palavras-chave: Direito à diferença. Direitos Humanos. Multiculturalismo.

\section{INTRODUÇÃO}

Como é possível dar um novo corpo a retórica universalística dos direitos humanos? Como iniciar um percurso cultural que faça justiça a hipocrisia subjacente de sua pretextuosa propaganda política?

Intervir e falar em nome dos direitos é desde já sintomático de um álibi cultural e de uma política estratégica que reconduz certas pessoas e certos povos a ser objeto de direitos humanos e não ao invés a ser sujeito.

Para desconstruir e reconstruir a concepção universalística dos direitos humanos seria necessário reexaminar a categoria de humano, de universal e de direito. A estratégia de articulação entre cada uma dessas categorias envolve uma constante prática de tradução histórica e cultural entre elas. Uma pratica participativa, transversal e circular, apontada na direção de um ethos auto-reflexivo.

Para uma autora como Judith Butler, por exemplo, "reelaborar o humano é, poderíamos dizer, uma incessante tarefa dos direitos humanos, na medida em que a sua presumida universalidade não tem um campo de ação universal" ${ }^{3}$.

A mesma coisa poderia-se dizer sobre a necessidade de reelaborar o universal, na medida em que a sua aspiração abrangente fala historicamente do reconhecimento da própria gênese política e cultural, da própria constitutiva incompletude, do reconhecimento das outras aspirações ao universal e da natureza parcial e conflittual dos direitos que alcançam pela sua realização. Para um autor como Makau Mutua, por exemplo, «As críticas ao corpus dos direitos humanos por parte de africanos, asiáticos, muçulmanos, hindus, e por um vasto conjunto de pensadores críticos de todo o mundo são a única via através da qual os direitos humanos poderão ser redimidos e verdadeiramente universalizados»" ${ }^{4}$.

Por último, o direito, do qual se remove habitualmente a sua condição de possibilidade pré-jurídica, o contexto sócio-antropológico que o determina com 
juízos de valores ancorados a específicas relações de poder dissimuladas, a sua volta, a presença de categorias desconhecidas e explicativas aparentemente neutras e abstratas. O uso neutro das categorias filosóficas esconde uma prática socialmente marcada de valorizações das ações e estigmatizações dos indivíduos, ou também uma situação de colisão nos agone político. A filosofia oculta, sem por isto poder remove-la completamente do próprio inconsciente disciplinar, uma genealogia impura do poder, anterior ao direito de julgar: a neutralidade do pensamento filosófico, como aquela do pensamento político, é só presumida e mistificada, enquanto abaixo dessa agem juízes hierarquizantes e performativos escondidos sob a pretensa superioridade da fria lógica racional.

\section{DESCONHECIMENTO E DISCRIMINAÇÃO POSTCOLONIAIS}

Decididamente, é plausível pensar que o destino relativo à maneira de habitar aquela que Edgar Morin chamou terra-pátria encontre uma divergência substancial na capacidade de acertar as contas com uma lógica obsessiva e possessiva do copertencimento e da identidade, sejam elas entendidas na sua declinação política ou religiosa, sexual ou étnica, geográfia ou econômica.

Um antropólogo como Clifford Geertz já tinha sintetizado esta tendência dos grupos humanos de exasperar ideologicamente a própria identidade através de categorias de exclusão e reivindicação: "as pretensões mais absurdas alegadas pelos homens nos confrontos da humanidade são sempre formuladas na linguagem do orgulho do pertencimento a um grupo ${ }^{5 "}$.

Todavia, a "civilização dos desencontros" - que parece se diferenciar como uma das cifras da modernidade avançada - emerge em face da contextualidade com a qual se promove a relação com o mundo sempre menos contornável. $\mathrm{Na}$ verdade, o sentido de propriedade pretendido acerca de uma disposição éticocultural qualquer é impróprio, porque alimentado por uma concepção fetichista da história e da identidade. Esse fetichismo identitário é interpretavel, entre outras coisas, como reação e paradoxal complemento de uma voraz lógica competitiva e colonizadora do capitalismo contemporâneo.

As práticas discursivas humanísticas que, nos últimos decênios, foram geradas em torno de questões como aquelas dos conflitos étnicos ou das diásporas migratórias, tanto da circulação transnacional dos fluxos econômicos e mercantis, quanto daqueles mediáticos e decisionais, do estado de exceção permanente ou da sociedade do risco, têm realmente encontrado a dialética mais apropriada no debate sobre globalização e transcultura.

A multiplicação de fenômenos culturais deslocantes, a sua irreversível intersecção e sobreposição em grande escala, a violência de uma razão econômica que não quer conhecer razões nem mediações, a desarticulação e a constante superação de todo âmbito tradicional e convenção da experiência social ordinária das últimas décadas estimulam a cultura crítica a uma nova série de problematizações sobre a natureza política da identidade cultural. 
A trama das relações culturais, ademais, aproxima-se constantemente com a sua sobreposição àquela das relações de poder.

Os direitos humanos refletiram, e ainda refletem, uma lógica similar. Como escreve o sociólogo Boaventura de Sousa Santos,

\begin{abstract}
Se observamos a história dos direitos humanos no período imediatamente a seguir à Segunda Grande Guerra, não é difícil concluir que as políticas de direitos humanos estiveram em geral ao serviço dos interesses económicos e geopoliticos dos Estados capitalistas hegemónicos. Um discurso generoso e sedutor sobre os direios humanos coexistiu com atrocidade indescritíveis, as quais foram avaliadas de acordo com revoltante duplicidade de critérios ${ }^{6}$.
\end{abstract}

Os direitos humanos universais são portanto um artefacto cultural do Ocidente, assim que "os direitos humanos são universais apenas quando olhados de um ponto de vista ocidental. Por isso mesmo, a questão da universalidade dos direitos humanos trai a universalidade do que questiona ao questioná-10 ${ }^{7 "}$.

A origem paradigmática destas narcisistas separações conceituais, correlatas a uma violenta discriminação sócio-política, ressalta na experiência da colonização e do paroveitamento sistemático das populações dominadas e culturalmente objetificadas.

As modernas democracias ocidentais são herdeiras de uma tradição - que já dura cinco séculos - na qual a modalidade de relacionar-se com o outro foi tendencialmente mantida por uma "violência epistêmica" que agiu em função da pretensão voltada à reprodução de um "original" através de uma "cópia", na reproposição de um "antes" em um "depois". A cultura ocidental apresentou-se e constituiu-se através desta violência relacional com o outro, com uma violência que reflete uma lógica de projeção narcisista do mais "forte" sobre o mais "fraco"; uma modernidade, então, que se converteu em sistema-mundo, da qual se tornou filosoficamente razão com um gesto ordinário de redução do plural das histórias locais ao "singular coletivo" da História".

Esta lógica dupla e discriminatória repercorreu e reproduziu-se dentro do mesmo coração ocidental dos modernos modelos republicanos de democracia européia. Formas de dominações hereditárias do passado colonial são sacudidas através do desconhecimento e da traição daqueles direitos de cidadania que o universalismo republicano proclama, mas que protege instrumentalmente poucos privilegiados.

A experiência histórica da democratização da cidadania se realiza parcialmente no quadro dos Estados-nação do norte europeu através dos conflitos sociais durados mais de um século. A cidadania social, isto é a extensão as populações nativas européias de maior segurança e benefícios para poder cultivar a própria independência e autonomia, tem dado sentido de realidade a cidadania política de modo nunca de todo completo e definitivo. Dentre das civilizações ocidentais se conservam zonas de sombra e feridas que na história recente são perigosamente ressurgidas, verticalizando a economia das relações sociais e negando, de tal modo, 
duplamente a universalidade daqueles direitos humanos, dos quais os princípios de cidadania deveriam ser o reflexo complementar.

Desenvolvendo os trabalhos de Ferdinand Braudel, Immanuel Wallerstein, tem mostrado como o capitalismo se está desenvolvendo no quadro de uma "economiamundo" que é essencialmente uma relação assimétrica de um centro com as suas periferias $^{10}$. Ora, esta assimetria não é só uma relação frente a regiões estrangeiras. Se criaram "periferias" nos centro das metrópoles ocidentais, uma classe do sul nas quais se acumulam discriminações de todos os tipos: pobreza, violência, racismo, insegurança social e civil.

Como sublinha Robert Castels para o caso dos banlieue francesi, as discriminações de raça e de classes sociais se cruzam e sobrepõe sempre mais, e os universalismos republicanos mostram o próprio lado deficitário também quando formalmente reconhecem a igualdade de todos os cidadãos. Antes de tudo:

É preciso sublinhar a relação que existe entre esta democratização da cidadania e a posição dominante que ocupam os Estados-nação que a colocam em prática e podem desenvolver programas sociais ambiciosos, ao menos em parte, porque se beneficiam de um sistema de trocas desiguais que procura seus recursos externos através de relações de domínio colonial, pois pós-colonial ${ }^{11}$.

Para Castels se assiste na França a uma radicalização da exclusão de cidadãos franceses com origem étnica e pertencimento religioso diversos:

\begin{abstract}
Os acontecimentos do outono de 2005 e os problemas das banlieues se inscrevem assim no quadro de uma questão que se agudiza sem pausa a qualquer ano. Esta verte sobre a presença, na sociedade francesa, de formas de dominações hereditárias do passado colonial que assinalam o tratamento das populações vindas de regiões em outros tempos postas sob a hegemonia francesa. De modo que um número crescente de representantes das minorias étnicas pensa seja chegado o momento de colocar frontalmente a questão: 'alguns cidadãos franceses são tratados como nativos da República'? [...]. É possível imaginar uma refundação do modelo republicano, assim como um alargamento da conceção da cidadania, que os torne capazes de constituir os princípios unificadores de uma sociedade pluriétnica e pluricultural? ${ }^{12}$
\end{abstract}

A cultura e a economia política do Ocidente se revelaram assim falsas também a respeito dos próprios cidadãos, degradando a credibilidade das próprias instituições e a coesão do tecido social de referência. Se, historicamente, o custo inicial da progressiva democratização da cidadania conduziu alguns Estados-nação a projetarem as próprias desigualdades e injustiças originadas fora, sobre o Sul do mundo, agora estes mesmos dispositivos discriminatórios caracterizam a experiência político-cultural da cidadania, assim dita democrática, no seu interior.

O modelo republicano, todavia, poderia abrir um horizonte mais ambicioso, aquele que Achille Mbembe caracteriza assim: "a força do nosso modelo de universalismo brotará da nossa capacidade de compreender que a ligação com 
aqueles que não são os nossos consiste, em larga parte, na experimentação de histórias comuns, sobretudo quando estas foram objeto de desconhecimento ${ }^{13 \text { ". }}$

\section{POR UMA ÉTICA DA TRADUÇÃO CULTURAL}

Uma longa série de eventos histórico-sociais, inerentes aos impulsos globalizantes dos interesses econômicos e das necessidades políticas das istituições, determina, portanto, uma desorientação e uma confusão entre contextos culturais habitualmente considerados domésticos, reconhecíveis, quase com uma segunda natureza, mas progressivamente evolventes para qualquer outra coisa; processos históricos que, além disso, implicam transformações estruturais de habitats institucionais consolidados. Dimensões da experiência como aquelas assinaladas pelos atuais processos migratórios, pela desestruturação do mundo do trabalho, pela escassez evocada dos recursos sociais e democráticos ou, ainda, pela demolição do papel decisional e simbólico das instituições políticas nacionais e supranacionais, são algumas daquelas "instâncias do heterotópico" que participam de tal âmbito histórico, caracterizando os seus conflitos e colocando as cartas que estão em jogo.

A problemática reconhecimento-distinção entre agentes e agências sociais resulta marcada pela exigência paroxística de definir constantemente as diversas identidades culturais, com relativos espaços de co-pertença política e normativa, num contexto histórico-político agora descentralizado, e pelas filiações disseminadas. Cada uma destas identidades, desvinculadas de um substancial "mundo comum", torna-se não-mais-diferente, perdendo aquela relação que a tornava diferente-por. A fluidez das pertenças culturais conduziu, por reação, a uma impetuosa busca das distinções e a uma demarcação obsessiva das diferenças no próprio centro de cada terriório nacional. Sobrepondo-se, as diferenças são percebidas imediatamente (paradoxal e nervosamente) como similares, à medida que menos distinguíveis, provocando, em seu conjunto, uma torsão entrópica das relações sociais, das quais um sintoma representativo é a conhecida rejeição de indivíduos e grupos, historicamente distantes (ou, ao menos, socialmente inscritos em categorias precisas), que se tornaram repentinamente muito próximos.

Destaca-se uma passagem necessária, no âmbito da crítica e da política, de uma concepção idealística do cosmopolitismo para uma hibridação diferenciada mais concreta. Há quem pode viver a hibridade como um luxo e quem pode vivê-la como uma ameaça, mas a natureza destas modalidades assimétricas de nos relacionarmos decorre, antes de tudo, de uma condição igualmente assimétrica de disponibilidade de acesso à gestão dos recursos culturais e políticos.

A mesma coisa acontece com os direitos humanos e com a pressuposta universalidade deles. Todos os grupos humanos e todas as culturas tendem a definir como universal os valores que consideram fundamentais. Neste sentido revela-se importante integrar o desafio epistemológico e político daquela «hermenêutica diatópica», proposta por Boaventura de Sousa Santos em relação a uma reconstrução intercultural dos direitos humanos, que «presuppõe a aceitação do seguinte imperativo transcultural: temos o direito a ser iguais quando a diferença nos inferioriza; temos 0 direitos a ser diferentes quando a igualdade nos 
descarateriza» ${ }^{14}$. Por Sousa Santos a hermenêutica diatópica pressupõe o reconhecimento da incomensurabilidade entre diferentes universos de sentido e também alcança o objectivo de tomar consciência da incompletude de todos os topoi que os caracterizam através de um diálogo entre eles:

\begin{abstract}
Tais universos de sentido consistem em costelações de topoi fortes. Os topoi são os lugares comuns retóricos mais abragentes de determinada cultura. Funcionam como premissas de argumentação que, por não se discutirem, dada a sua evidência, tornam possível a produçãp e a troca de argumentos. Topoi fortes tornam-se altamente vulneráveis quando «usados» numa cultura diferente. O melhor que lhes pode acontecer é serem despromovidos de premissas de argumentação a meros argumentos ${ }^{15}$.
\end{abstract}

A vulnerabilidade das identidades culturais è tanto constitutiva quanto conjuntural. O diálogo entre culturas è possível na medida em que a vontade deste diálogo seja sustentada por um ethos de reciprocidade. Existe uma intrínseca incoerência política entre os diversos níveis de hibridação cultural: uma enorme diferença separa homens de negócios ou intelectuais cosmopolitas, que podem experimentar interações diversificadas sem que a própria cultura e indentidade sejam colocadas em discussão, e outros sujeitos que (de baixo e imediatamente) vivem a interação com mundos desconhecidos como uma constrição angustiante. Mesmo em relação aos direitos humanos universais:

\begin{abstract}
Sendo a questão da universalidade a resposta a uma aspiração de completude, e porque cada cultura "situa» esta aspiração em torno dos seus valores fundamentais e da sua validade universal, aspirações diversas a diferentes valores fundamentais em diferentes culturas podem conduzir a preocupações isomórficas que, dados os procedimentos de tradução intercultural adequados, se podem tornar mutuamente intelegíveis. $\mathrm{Na}$ melhor das hipóteses, será mesmo possível conseguir uma mestiçagem ou interprenetração de preocupações e concepções. Quanto mais igualitárias forem as relações de poder entre culturas, mais provável será a occorência desta mestiçagem ${ }^{16}$.
\end{abstract}

Em busca de um objetivo semelhante é que se propõe a categoria da tradução cultural como a atividade de um saber em movimento entre outros níveis de mediação: atividade reflexiva que alcança seja o plano das relações intersubjetivas, seja aquele dos percursos intrasubjetivos e, contextualmente, o exercício de estima e de verificação das forças que marcam o campo sobre o qual tais mediações se realizam. Uma ponte circular de elaborações diferentes, mas conexas. Traduzir, nessa esfera, significa levar em conta a sua dúplice acepção, ativa e passiva, de ser traduzido e de ser agente de tradução. A co-presença destas duas modalidades, intrínsecas à prática da tradução, é simbolicamente representada pelo seu próprio prefixo: tra (entre, intra, inter); traduzir consite, portanto, em acertar as contas com aquele contigente todo em torno, sendo inevitavelmente aquilo que é o nó e a refração de uma rede heterogênea de relações.

Não se trata de discorrer necessariamente sobre a transferibilidade de sentido de um texto, ou de um enunciado, de uma língua à outra, mesmo porque, caso 
quiséssemos permanecer no interior da topologia lingüística, poder-se-ia retomar as observações já feitas sobre a tradução como movimento imanente de toda língua singular, uma vez que em toda linguagem opera sempre "um modelo de trans-lação, de transferência vertical ou horizontal" "17. Portanto, além do modo como no interior da própria cultura lingüística se encontram passagens contínuas e intermediárias de tradução entre termos que, em si, já remetem um ao outro, a atenção aqui se coloca sobre a transposição de tais passagens no âmbito da codificação excedente a semiose lingüística, em contextos de práticas e operações culturais que atravessa mais planos discursivos, em que as próprias línguas se revelam instrumentos de um "saber-fazer" relacional mais complexo.

Evitando todo tipo de reductio ad unum, a tradução cultural pode ser concebida, então, como condição e expressão de relações transculturais, como pressuposto tácito que opera em toda situação de co-presença, como fronteira móvel e sinalizadora da relação que cada um mantém consigo mesmo. Ponto de encontro destas diversas dimensões da experiência, a tradução cultural pode colaborar na construção de um projeto ético-político específico, levado a cabo na compreensão aproximada do próprio contexto de tradução, manifestando e filtrando aquelas lógicas que, de qualquer modo, o pré-ocupam.

Em princípio, a tradução cultural pode manifestar-se favoravelmente, mediante uma ponderação sobre a efetiva condição relacional, numa apreensão para 0 destino das cartas colocadas em jogo e para o reconhecimento recíproco das diferenças entre quem age; implica, em suma, uma autoavaliação reflexiva. É preciso, então, analisar o terreno sobre o qual se cultiva tal experiência atualmente, reconstruir os seus panoramas históricos e críticos, e, ao mesmo tempo, verificar como e onde se tornam articuláveis. O humano inscreve-se sempre como marca cultural de um evento social ou discursivo; historicidade significa reconhecer que tudo aquilo que é humano precisa de tradução. Por exemplo, uma concepção como aquela pirandelliana da «vida nua», mencionada em 1908 no ensaio sobre 0 humorismo, e retomada por Agamben em «nua vida», revela-se portanto espiritualista, porque a vida tem sempre um vestido, também quando parece transparente!

Os contextos em torno dos quais se condensa a maior problematicidade e dos quais se irradiam as tensões cognitivas e afetivas mais delicadas são aqueles interessados pelos intrincados processos econômico-culturais das "diásporas", da "fragmentação" e da "despolitização" do poder. Mais ou menos diretamente, os analistas sociais que debatem a respeito do tecido da socialidade atual não podem deixar de acertar as contas com aquele "território" definido por alguns como slippery, desarticulado, diferenciado, escorregadio, mas também sincrético, que ao mesmo tempo o envolve e o excede, que é o "nosso" horizonte cultural.

O caráter meta-histórico da prática tradutora se torna, nesse contexto, um instrumento insidiado e afixado por uma compressão dos processos sócio-culturais que, incindindo sobre todo ser histórico e configuração mental, constringem a rápidas e difusas readaptações locais de sentido, cumulando, por sua vez, contínuos efeitos descentralizadores. Aquilo que perturba a disposição tradutora, contudo, não é tanto a descentralização ou a readaptação enquanto tal, já que desde sempre o ser humano debate com (e se nutre de) estas condições inelutáveis da experiência, 
mas o cenário no interior do qual estas experiências se apresentam e as modalidades através das quais se intensificam: um contexto histórico-político baseado no primado da contingência, condicionado por dinâmicas que tornam tal compreensão de eventos injustificável, imprevisível efeito de remotas relações de força experimentadas como anônimas e, no final, gerando uma sensação de impotência política que é determinada na experiência difusa do mundo social como algo em que nada de verdadeiramente importante ou decisivo pode acontecer.

Ademais, essas dinâmicas vêm integradas no interior de um quadro tautológico da representação social. Uma representação pré-julgadora, em que aparentemente se tem tudo em uma agenda simbólica e pública que organiza um consenso de fundo, ou seja, aquele "conjunto de evidências compartilhadas que são constitutivas do sentido comum", que, por sua vez, informa por si (traduz) as categorias reconhecedoras (tradutoras), os "esquemas práticos de percepção, de valoração e de ação"18.

Assim, nos movemos em torno de questões que diversamente remetem aos êxitos dos aristotélicos éndoxa, da colonização das consciências e do domínio simbólico, etapas ou deslizes da experiência individual e coletiva da qual se trata de registrar e historicizar o vínculo com a atual fenomenologia de um poder exercitado "segundo as técnicas de tratamento homeopático e da metabolização do desejo"19. É preciso, portanto, paralelamente, confrontar-se com os "discursos" de quem, operando na justificação do existente, institui um "vocabulário de fundo" que sustenta e vincula os juízos, as representações e as molduras do reconhecimento, pré-especificando as gramáticas cognitivas e emotivas através das quais se concebem e agem as várias relações sociais.

Estudiosos como Ludwig Wittgenstein ou Pierre Bourdieu nunca deixaram de indicar que as discussões em torno dos métodos e dos sistemas de classificação não devem fazer com que se esqueça que todo instrumento de conhecimento também se reveste de funções que não são de puro conhecimento. Os modos convencionais de conhecimento e de expressão estão sempre ancorados "nas condições sociais da sua produção e reprodução"; as "práticas taxinômicas, instrumentos de conhecimento e de comunicação que são as condições da constituição do sentido e do consenso sobre o sentido e que não exercitam a sua eficácia estruturante senão estão, por sua vez, estruturadas" ${ }^{20}$.

Somente através de um corte gramatical na estrutura deste tipo de vocabulário, fundamental para reconstruir "o arbítrio histórico da instituição histórica que se faz esquecer como tal, tentando fundar-se numa razão mítica" ${ }^{21}$, a crítica pode se aproximar mais livremente de um horizonte de inspiração cooperativa entre as diferenças.

\section{A POLÍTICA UNIVERSALISTA DA DIFERENÇA}

Assim como não pode existir uma prática reconhecedora intersubjetiva que não inclua contemporaneamente (mas não por isso sincronicamente) um complexo reconhecer-se intrasubjetivo, também não pode existir tradução cultural que não compreenda dinâmicas autotradutoras, conhecimento da própria forma de 
conhecimento. Ao contrário, nenhuma prática de individualização é possível sem traduzir e reconhecer a própria tradição de co-pertença e a estrutura do espaço social no interior do qual se age e se prefere. Trata-se, com efeito, de um processo circular que exige um trabalho compartilhado.

Toda prática tradutora é também (quando não se fecha em movimentos centrípetos que afastam) uma ficção da hibridação. Operar em um espaço aberto à possível realização de imprevisíveis soluções necessita, como já referido, de paralelos processos de reconhecimentos, que, por sua vez, implicam as sociologias reflexivas sobre o espaço social de ação. Operações que (para quem com elas está diretamente envolvido) não são necessariamente resultado de projetos deliberados, que podem não passar pela mediação consciente da consciência, mas que, não obstante isso, agem freqüentemente no cotidiano como sábia ignorância através de uma série de insistentes solicitações práticas.

Todo fenônemo cultural "pode ser lido somente a partir dos seus significados locais, gerados no interior do próprio espaço social" 22 ; toda leitura extrínseca ou desconhecedora das relações constitutivas deste espaço tenderá sempre a interpretar os fatos que recaem sobre ele considerando os significados associados à posição de quem os observa.

O destino da ética tradutora depende do uso de fundo das categorias reconhecedoras, da sua permeabilidade às situações, da receptividade e da expressividade no que diz respeito ao sentir próprio e ao sentir dos outros, da sua capacidade de integrar mais olhares sobre o mesmo espaço social, do modo e da freqüência com que, em determinados contextos, tais categorias são aplicadas ${ }^{23}$.

A ocasião representada pela emersão contemporânea de subjetividades transculturais - não obstante os ambientes em que se geram, no mais das vezes, serem o palco de sofridas colisões entre pessoas e grupos divididos por interesses e habitus diversos - oferece a possibilidade de pensar uma política universalista da diferença ${ }^{24}$, sob uma pespectiva ética intermediária em relação aos pólos extremos de um "comunitarismo" que hipostasia as diferenças e de um "neoliberalismo" individualista.

Tratar-se-ia de transpor, à cultura e à prática política baseadas no direito, o reconhecimento daquelas condições concretas que tornam conveniente e realista a mediação e a co-existência entre sujeitos portadores de novos direitos particulares e de diferentes valores fundamentais. Promover um lobby democrático e garantir a universalidade das estragégias de universalização.

O acesso aos benefícios sociais e civis oferecidos pelas categorias democráticas da igualdade e do universal é, cada vez mais, desigual; daí a promoção de uma estratégia geral de generalização do direito como sua tradução em direitos, como abertura à exigência de legitimidade universal proveniente de instâncias particulares ${ }^{25}$.

Aproveitar estes sintomas quer dizer promover aquela socialidade que é indiscernível para uma busca de individualização por parte dos singulares, aquela que tem como premissa necessária a dupla implicação entre indivíduos e grupos de 
referência que se procuram e se constituem através dos outros. Trata-se de retomar - e praticar por extenso - a velha e basilar lição aristotélica, segundo a qual se é humano somente na medida em que se pertence a um grupo social (o animal político), e de revisitar aquela racionalidade prática que se manifesta em situações (phronesis). "A socialidade é o âmbito de um tornar-se em que o grupo e o indivíduo do grupo não param de procurar um caminho próprio, e tal busca constitui o tempo humano" ${ }^{26}$. A individualização é precisamente o resultado parcial de uma circularidade entre tempos: "embora não seja, com certeza, o tempo do nós, o tempo do eu desenvolve-se no tempo do nós, que é, por sua vez, condicionado pelo tempo dos eus que o compõem"27.

O imundo prospera na remoção destas passagens de troca, na incapacidade de traduzir a interferência ou a interdependência em dispositivos emancipatórios, na impaciência ou na má-vontade de se pensar, juntamente, interligados e separados.

Resulta fértil, portanto, referir-se àqueles âmbitos em que os encontros entre diversas histórias e habitus ocorrem, aparecem inventivos e determinam a maturidade de uma co-existência real. No mais das vezes, são âmbitos cotidianos de relação prática, ambientes que favorecem o reconhecimento espontâneo das situações do próprio encontro, microcosmos de participação em que se concretizam disposições psicológicas dúcteis no articular a proposição de si com a discrição, a autorepresentação com a reciprocidade (dir-se-ia contextos capazes de gerar response-ability, concern ou acknowledgment).

São situações que se produzem às margens dos grandes relatos da globalização, o que também contribui para fornecer o seu palco local e, ao mesmo tempo, são movimentos de resistência e transformação, experimentos de uma mediação multilateral que se joga entre outros contextos e outros imaginários. "Estas relações permitem a articulação daquela experiência de mutamento típica de sociedades desarticuladas pelo desenvolvimento da modernização e, então, facilitam o avanço das exigência de transformação social" ${ }^{28}$.

Nesta esfera do agir prático e da contigüidade entre linguagens estranhas, a tradução apresenta-se como uma experiência de trânsito compartilhada entre benjamianos "espaços contínuos de transformação, não abstratas regiões de igualdade e semelhança" ${ }^{29}$; experiência que se inicia com maior intensidade quase sempre de baixo e que, enquanto tangivelmente cansativa pelas dificuldades culturais e pelas profundas dimensões da conflitualidade, em certos casos, traça percursos de socialidade e adapta formas de comprometimento. A isso corresponde o risco, mas também a oportunidade de descobrir a incoerência subtancial de toda narrativa cultural, assim como a inutilidade de buscar soluções consensuais definitivas.

São ambientes em que prevalece a "lógica das coisas" acima das "coisas da lógica": "Modos de ser da troca (e de uma certa inclinação à hibridação) que não devem ser sobrevalorados, mas que têm o mesmo direito de existência - no território da imaginação em que assumem, preliminarmente, forma de idéias com as quais reconfiguramos a cultura, a história e a sociedade - daquela outra tendência, nos dias de dominante, segundo a qual a cultura seria alguma coisa fixa, determinante, 
uma espécie de maldição ou de benção que nos acompanha do nascimento à morte" 30 .

\title{
4 O DIREITO DE RECONHECER-SE HUMANOS
}

Uma questão aparentemente estranha tem feito pano de fundo a esse escrito: das "leadshirp" contemporâneas dos países hegemônicos e das maiores instituições internacionais não parecem emergir culturas políticas movidas pela perquisa de uma nova relação com os problemas sociais das desigualdades, das discriminações e do aproveitamento ambiental. Se tende invés a fechar-se na contemplação do próprio domínio ou no ocultamento da própria inércia administrativa, acreditando substituir o governo com o comando e a política com o poder carismático. Uma questão que solicita respostas globais, divergentes mas combinadas a lúcida necessidade que precisa dar urgentemente espaço aquelas epistemologias e aquelas práticas sociais inspiradas na construção de uma nova educação sentimental e do reconhecimento de cada destino como pertencente a uma "comunidade de destino".

Seguindo um propósito símile, com mérito as realizações de "uma cultura dos direitos humanos", um autor como Ricador Rorty se pergunta: "O que fazer de nós? Que tipo de mundo queremos construir para os filhos dos nossos netos ${ }^{31}$ ?" Para Rorty, se existe qualquer coisa que combina os seres humanos entre eles precisa procura-la naquela capacidade de ser plásticos e maleáveis, tanto nas disposições cognitivas quanto naquelas emotivas. Experimentar sentimentos, complexos e ambivalentes, é o seu basilar trato distintivo; empenhar-se em causas comuns é uma potencialidade inscrita na nossa antropologia, sem por isso ser deduzida a sua tradução na atualidade. Para Rorty, ${ }^{32}$

\begin{abstract}
Mais duras são as condições de vida, maior é a quantidade de coisas que fazem medo; mais perigosa é a existência, mais diminuem o tempo e a vontade de imaginar como pode ser a vida das pessoas com as quais não existe uma identificação imediata. A educação sentimental funciona somente onde a gente é bastante relaxada a permitir-se ouvir. [...] Este progresso (da educação sentimental) consiste em uma mais acentuada disponibilidade de reconhecer os elementos de semelhança entre nós e as pessoas diversas de nós um peso maior do que aquele que tem os elementos de diferenciação. Tal seria, então, o resultado daquela definida 'educação sentimental'. As semelhanças que contam, neste caso, teriam bem pouco a ver com o compartilhamento universal de um si é verdade ou abaixo da superfície e instância primeira de uma humanidade verdadeira, coincidindo ao invés com tantas pequenas semelhanças de superfície, como por exemplo o afeto para os genitores e para os filhos ${ }^{33}$.
\end{abstract}

Aquela de Rorty é, sem dúvida, uma visão otimista, não sempre de fato a atenção e o interesse pela diversidade brotam de uma classe de benefícios exonerante das preocupações cotidianas. Pelo contrário, como demonstram os racismos e as indiferenças contemporâneas, muitas ignorâncias sentimentais emergem e se propagam do coração mesmo das elites metropolitanas do Ocidente. Todavia, é importante sublinhar a importância que pode ter concentrar a potencialidade da cultura dos direitos humanos não nos fundacionismos antropológicos (as variantes biológicas da espécie humana), quanto no terreno histórico que constantemente as cultiva como qualquer coisa de precioso. Com 
efeito, sublinhando o significado etimológico da palavra cultura, a qual provém do latim colere, que quer dizer tanto "habitar" quanto "cultivar", se pode escavar um nexo que conduz sobre uma crítica da clássica noção de natureza. A natureza não tem uma dimensão ontológica universalmente válida, mas seria essa mesma um produto cultural: é em suma uma natureza já habitada e cultivada.

Ocorre, então, ter sempre presente que certos dispositivos antropológicos, ainda que naturalmente propícios a implantação do recíproco reconhecimento, podem não ter lugar. A mesma noção de humanidade, de resto, não se confunde com um modelo ideal qualquer (ser humanos como fim em si), que fugiria do critério de distinção entre isto que é humano e isto que não é. Precisa dissipar a impressão desviante que exista uma entidade (naturalística) isolável e claramente indentificável que se chama "humanidade"; as mesmas tipologias mediantes as quais o ser humano se manifesta são reencontráveis nas nossas mesmas reações a este que é humano (o campo de concentração é um exemplo), no sentido que estas reações não podem considerar-se naturais. Ou melhor: não podem ser garantidas pela natureza ${ }^{34}$.

Não se pode definir a humanidade em termos rígidos, referindo-se a um princípio moral geral. Precisa recordar, ao contrário, que os nossos modos de responder aos outros são:

o produto do complexo das atividades humanas através das quais viemos a formar os conceitos de vida humana e de ser humano como qualquer coisa de especial [...]. E é esta história a hereditariedade a representar a partida sob a qual faz trabalhar a reflexão moral. Portanto serão não as diferenças em si a ditar-nos intrinsecamente o que devemos fazer, mas será aquilo que fizemos de tais diferenças que pode ser valorado em termos morais ${ }^{35}$.

Não é por menos, relativamente a insurgência do direito humano, e do direito humano enquanto direito universal, que se pode igualmente aproximar a uma sua especificação orientada a compreender alguns fatores ligados a sua possível gênese sócio-antropológica. A que coisa responde o direito e o direito humano? Qual exigência antropológica ou organizativa encerra em si? Qual afirmação de desejo traz a luz manifesta?

Tentar responder não é fácil, em primeiro lugar porque não pode ser uma resposta universalmente válida; a história humana coleciona diversas experiências para poder-Ihes indicar algumas como exaurientes de todas as outras. Todavia, fazendo referência a alguns "universali empirici" (universais empíricos) , aqueles que assinalam como cada hábito cultural é enfronhado de uma biologia que ao mesmo tempo permite e pretende socialização, se podem traçar algumas pistas de reflexão úteis para compreender como certos direitos nascem e se definem.

Uma primeira reflexão é de matriz pascaliana: aquela pela qual uma sociedade, uma instituição, uma lei, em breve, uma entidade "terceira" encarna uma ideal riserva aurea e que, por isto, resulta titular daquele capitale simbolico necessário a conferência, mais ou menos direta, de "justificação" para cada ser social ("problema indissolúvel, escatológico e sociológico) ${ }^{36}$. 
Uma segunda reflexão pertence a atenção para as fragilidades que o ser humano traz consigo como constitutivas. Na trama das primeiríssimas relações sociais se jogam delicados equilíbrios para o futuro da psique do ser humano: a experiência do reconhecimento e da reciprocidade lhes é um emblema, e tal emblema pode ser motivo de lutas para o reconhecimento como estratégias vitais de valorização.

Como mostra um psicanalista como Bruno Bettelheim, os sujeitos autistas não possuem o sentimento de serem parte ativa de um diálogo construtivo próprio porque cada iniciativa sua e expectativa comunicativa - iniciativa e esperança que no estado infantil é "ao mesmo tempo afetiva e cognitiva, nutricional e libidinosa, corporal e simbólica" - ficou iludida, frustrada ou o correspondente de modo inadaptado, mecânico, genérico, aproximativo. Recordando como traço caracterizador comum a todos os sujeitos autistas seja, com graduações diferentes segundo os casos, o seu sentimento de depender, passivamente e completamente, de uma força iminente como um "Destino" ou um "Ser imprescrutável" que o domina e o faz agir, Bettelheim especifica:

\begin{abstract}
Isto significa que para alcançar a psicose basta que uma criança (que enquanto tal nunca teve a possibilidade de desenvolver uma personalidade estável) esteja convicta que a sua existência é guiada por forças irracionais e imodificáveis que tem sobre ela direito absoluto de vida e de morte. Ao contrário, para que um adulto normal chegue a desenvolver reações psicóticas deste tipo, tal correspondência deve verificar-se realmente na realidade, próprio como acontecia nos campos de concentração ${ }^{37}$.
\end{abstract}

A atenção e o interesse nos confrontos de estilos das relações interpessoais através das quais se forjam as identidades, assim como a prudência e a discrição com que se interage nas trocas comunicativas, agem como função pedagógica.

\footnotetext{
Não se pode, de fato, forçar uma criança a falar, no sentido de comunicar, pois que a linguagem se adquire só na medida em que se estabelecem as relações pessoais. Impor a uma criança a ecolalia premiando-a ou punindoa não pode mais do que conduzi-lo a uma sempre maior desumanização ${ }^{38}$.
}

A terceira reflexão tem uma matriz arendtiana: aquela pela qual "parece que um homem que não é nada mais que um homem tenha perdido as qualidades específicas que fazem possível aos outros trata-lo como um homem igual a eles ${ }^{39 " .}$.

Que se seja capaz de ver e representar uma alteridade interna no homem é a garantia de uma cultura de direitos humanos. Sobre esta expectativa Jean-François Lyotard tem elaborado um pensamento próprio sobre "direitos dos outros". Partindo da experiência da faculdade de linguagem, da sua difícil iniciação e articulação na condição infantil como representativas de um sofrimento de exclusão da comunidade adulta dos falantes, Lyotard tem comparado a experiência de abjeção como aquela da qual dever-se resgatar através do acesso ao direito a palavra.

A objeção, em tal prospectiva, não é um fato episódico. 
Por isto a abjeção é uma condição inata da relação que os seres humanos instauram com a experiência comunicativa e a interlocução. As crianças são tidas as margens da interlocução e condenados ao exílio. A condição da infância é aquela do ser humano incompleto, que não sabe ainda falar. A criança fala e se fala dela, mas ela não é um interlocutor, porém sendo inserida a força na comunidade interlocutória. As afirmações que a consideram não tem valor para ela, se não enquanto sinal ou gesto; Ihe resulta difícil decifrar porque são arbitrárias, e ela te pouco instinto. Certo Ihe ressente o efeito, mas não possui uma linguagem que lhe permita articular os seus próprios estados afetivos, e estes subsistem dentro dela inconscientemente, em um esquecimento que é sempre presente, sem nunca entrar na temporalidade associada as instâncias do eu e do $t u^{40}$.

De tais condições de prematuridade descende uma angústia muda, e é a ela que devemos a capacidade de colocarmo-nos interrogativos sobre todas as coisas que nos circundam, mas também a nossa necessidade de ser bem acolhido, "a exigência de ser autorizados" a entrar e fazer parte da comunidade dos falantes.

\begin{abstract}
$\mathrm{Na}$ interlocução se desenrola o drama entre o mim e o vós: é o drama da autorização. A pergunta ou a afirmação que dirigimos aos outros são invariavelmente associadas a um pedido: libera-me da minha condição de abandono, deixa que comece a fazer parte de vós. Este pedido pode imprimir-se em uma ampla variedade de formas: amizade, ódio, amor, até mesmo indiferença. Mas nessa reside o fundamento do direito de falar, pois que é este direito a dar-me a certeza que a minha demanda será ouvida, e que não será rejeitada na objeção da infância. ${ }^{41}$
\end{abstract}

Uma última, mas não última, reflexão é aquela que vê na violação originária de um direito a experiência disso como um "resto" que resiste, por contraste, a sua inviabilização. Um direito latente a ser reconhecido e a reconhecer-se sujeito afectivo e cognitivo, e não objecto indiferente, de reconhecimento. Retornando a matriz violenta da colonização capitalista, Boaventura de Sousa Santos afirma como "cada direito tem fundamentos reconhecidos e fundamentos subterraneos, clandestinos e invisiveis". Em relação aos direitos humanos, estes direitos se podem pensar como «ur-direitos" "2: "normatividades originárias que o colonialismo ocidental e a modernidade capitalista suprimiram da maneira mais radical, de forma a erigirem sobre as suas ruínas, a estrutura monumental dos direitos humanos fundamentais" ${ }^{\prime 4}$. A comprensão destes direitos originarios exigiria

um exercicio de imaginação retrospectiva radical porque consiste em formular negatividades abissais. Implica denunciar um acto abissal de negativismo no âmago da expansão colonial, uma negatividade abissal na qual a modernidade Ocidental se baseou para erigir as suas deslumbrantes construções epistemológicas, políticas, económicas e culturais. Por isso, os ur-direitos não são direitos naturais, são direitos de naturezas cruelmente desfiguradas que existem apenas no processo de serem negados e enquanto negações. Reivindicá-los é abrir o espaço-tempo para uma concepção pós-colonial e pós-imperial de direitos humanos. ${ }^{44}$ 


\section{THE RIGHT TO BE SUBJECT OF RIGHTS}

\section{ABSTRACT}

The present text has for objective discuss the human rights deconstructing and reconstructing the universalistic conception of them and noting that to do so is necessary to reconsider the category of human, universal and law. The strategy of articulation between each one of those categories involves a constant practice of cultural and historical translation between them. A participatory practice, transverse and circular, pointed toward an ethos of self-reflection.

Keywords: Human Rights. Multiculturalism. Right to difference.

\section{NOTAS}

1 Tradução do italiano para o português de Fabiana Marion Spengler.

2 Investigador- Pós-doutorando do Centro de Estudos Sociais da Universidade de Coimbra (Portugal), no âmbito do programa de formaçaão avançada da Fundação para a Ciência e Tecnologia, sob a supervisão do Prof. Dr. Boaventura de Sousa Santos. Doutor em Ética e Antropoligia (Lecce/Itália). Mestre em Antropologia (Nantes/França). Especialista em Sociedade, Política e Conflitos Culturais (Pucrs/Brasil). Graduado em Sociologia (Roma/ltália). Autor de Professione essere umano (Besa, 2008) e Apparteneze sconosciute (Riuniti, 2007), além de inúmeros artigos em revistas internacionais. E-mail: vaniabaldi@ces.uc.pt. Endereço: Universidade de Coimbra - Centro de Estudos Sociais - Rua José Falcão - 239859900 Coimbra - Portugal.

3 BUTLER, Judith. Vite precarie. Violenza, lutto, politica. Roma: Meltemi, 2004. p. 115

4 MUTUA, Makau. Savages, Victims, and Saviors: the Metaphor of Human Rights. In: Harvard International Law Journal. v. 42. Cambridge: Publications Center - Harvard Law School, 2001. p. 243

5 GEERTZ, Clifford. The Interpretation of Culture. New York: Basic Books, 1973. p.22

6 SANTOS, Boaventura de Souza. A gramática do tempo: para uma Nova Cultura Política. Porto: Afrontamento, 2006. p. 411.

7 SANTOS, Boaventura de Souza. A gramática do tempo: para uma Nova Cultura Política. p. 410.

8 A respeito do tema, merecem destaque as reflexões de Mario Perniola sobre a natureza do "transito dallo stesso allo stesso"; a crítica a esta idéia de tradução, também na sua versão lingüística, é reconduzida à secundariedade debitada à experiência do presente temporal e da presença espacial: "o ato de traduzir implica que o original e a tradução sejam ao mesmo tempo, ou pelo menos, sejam estensões do mesmo tempo, e este não pode ser nada além do presente" (PERNIOLA, Mario. Transiti. Filosofia e perversione. Roma: Castelvecchi, 1998. p. 36). A natureza do trânsito é muito familiar àquela que se vai propor para tradução. O presente não é o instante pontual, mas o conjunto daquilo perante o que se está presente, isto é, perante o que se está inter-essado.

9 A referência é a Reinhart Koselleck (Futuro passato. Per una semantica dei tempi storici. Genova: II Melangolo, 1986). Segundo o filósofo alemão, a modernidade ocidental estruturou-se sobre uma concepção de sentido histórico configurada em torno de um vetor temporal de unidirecionalidade e linearidade, ou seja, de uma indistinta metafísica progressista, sobre a qual se implantou uma constante tensão entre "horizonte de expectativa" e "espaço de experiência". A crise histórica da constelação simbólica da temporalidade cumulativa e irreversível, de matriz hebraico-cristã, conduz na direção de um experiência mundanizada e secular do se tornar histórico; esta reconfiguração da semântica histórica geraria um horizonte de sentido no interior do qual se radica, como se verá melhor em seguida, uma tonalidade emotiva considerada pós-histórica, 
caracterizada, portanto, por um sentido de esvaziamento da carga simbólica do futuro, pela sua redução a um dejà vu ou a um futuro passado.

Também cf. SANTOS, Boaventura de Souza. Para além do Pensamento Abissal: das linhas globais a uma ecologia de saberes. In: Revista Crítica de Ciências Sociais. v. 78. Coimbra: Centro de Estudos Sociais da Universidade de Coimbra, 2007.

WALLERSTEIN, Immanuel. The capitalist World-economy: Essay. Cambridge: Cambridge University Press, 1979.

CASTEL, Robert. La discriminazione negativa. Cittadini o indigeni?. Macerata: Quodlibet, 2008. p. 111; La Discrimination négative. Citoyens ou indigenes? Paris: Éditions du Seuil, 2007.

CASTEL, Robert. La discriminazione negativa. Cittadini o indigeni? p. 79-80.; La Discrimination négative. Citoyens ou indigenes?

MBEMBE, Achille. La République et l'impensé de la race. In: BLANCHARD, Pascal; BANCEL, Nicol; LEMAIRE, Sandrine. La Fracture coloniale. La société française au prisme de l'héritage colonial. Paris: La Découvert, 2005. p. 157. ST SANTOS, Boaventura de Souza. A gramática do tempo: para uma Nova Cultura Política. p. 414. SANTOS, Boaventura de Souza. A gramática do tempo: para uma Nova Cultura Política. p. 410. STEINER, George. Dopo Babele. II linguaggio e la traduzione. Milano: Garanzi, 1994.

BOURDIEU, Pierre. Meditazioni pascaliane. Milano: Feltrinelli, 1998. p. 184

19 Assim é que Giacomo Marramao re-traduz o início da Minima moralia adorneana. Ver, para tanto, MARRAMAO, Giacomo. L'oltrepassamento della soglia dei desideri e la normatività della sofferenza. In: AA.VV. Nuove frontiere del diritto. Bari: Dedalo, 2001. p. 75. BOURDIEU, Pierre. II senso pratico. Roma: Armando Editore, 2005. p. 147-148; também, WITTGENSTEIN, Ludwig. Lezioni e conversazioni sull'etica, l'estetica, la psicologia e la credenza religiosa. Milano: Adelphi, 1972. Pierre Meditazioni pascaliane. p. 100

\section{Postcolonialism. A very Short Introduction. Oxford: Oxford University Press, 2003.}

Cf. SPARTI, Davide. Oltre la politica del riconoscimento. Per una rilettura del nesso identità/riconoscimento a partire da Hannah Arendt e Stanley Cavell. In: Teoria Politica. n. 2. Milano: Franco Angeli, 2005. p. 107-131.

Ver, para tanto, MARRAMAO, Giacomo. Passaggio ad Occidente. Filosofia e globalizzazione. Torino: Bollati Boringhieri, 2003. É importante sublinhar como o colocar em foco esta proposta encontrou um decisivo aprofundamento na ação desenvolvida pelos estudos pós-coloniais. somente retórica, uma vez que vincula eticamente os sujeitos que nela estão representados. Cf. STIEGLER, Bernard. Passare all'atto. Roma: Fazi, 2005. p. 9, onde há referências explícitas à obra de Gilbet Simondon sobre a individualização psíquica-coletiva (individuazione psichicacollettiva). STIEGLER, Bernard. Passare all'atto. p. 10.

Cf. YOUNG, Robert J. Introduzione al postcolonialismo. p. 97. A propósito, cumpre referir os emblemáticos estudos de Arjun Appadurai acerca dos efeitos da modernity at large sobre as transformações da experiência da localidade, dos imaginários e das filiações culturais. BENJAMIN, Walter. Sulla lingua in generale e sulla lingua dell'uomo. In: Angelus Novus. Saggi e frammenti. Torino: Einaudi, 1995. p. 64, para quem a tradução é dada por uma continuidade de transformações que passam entre aqueles que denomina "meios de espessura diversa", "isto é, gradualmente".

DAL LAGO, Alessandro. Esistono davvero i conflitti fra culture? n. 421, Bologna: II Mulino, maio 2005.

31 RORTY, Richard. Human Rights, Rationality, and Sentimentality. In: SHUTE, S.; HURLEY, S. (Org.). On Human Rights - The Oxford Amnesty Lectures 1993. New York: Basic Books, 1993. p. $112-134$

RORTY, Richard. Human Rights, Rationality, and Sentimentality. In: SHUTE, S.; HURLEY, S. (Org.). On Human Rights - The Oxford Amnesty Lectures 1993. p. 112-134

33 RORTY, Richard. Human Rights, Rationality, and Sentimentality. In: SHUTE, S.; HURLEY, S. (Org.). On Human Rights - The Oxford Amnesty Lectures 1993. p. 145-146.

34 Precisa sempre ter presente que isto que é humano o é enquanto partícipe de uma específica forma de vida. Escreve Silvana Borutti em um artigo emblematicamente intitulado Wittgenstein impolitico?: "enquanto estrutura de acordo e de reconhecimento intersubjetivo, a forma de vida não é de pensar em um espaço de anterioridade lógica e histórica, não é fundamento no sentido 
de uma cena primária, de um acordo acontecido e distante no lugar sem tempo de origem. $A$ forma de vida é entre nós, é a estrutura nômade e dinâmica do acordo que torna possível o constituir-se de uma comunidade"; In: SPARTI, Davide (a cura di) Wittgenstein político. Milano: Feltrinelli, 2000. p. 147.

35 SPARTI, Davide. L'importanza di essere umani. Etica del riconoscimento. Milano: Feltrinelli, 2003. p. 145-187. Sparti não utiliza tais conceitos nem no sentido da Achtung kantiana (igual respeito), nem no sentido dea Anerkennung hegeliana (reconhecimento recíproco); "o ser empregado é ao invés o termo reconhecimento prático", entendido como "tradução aproximada" do termo inglês acknowledgement.

36 Uma síntese com a qual Pierre Bourdieu recupera as observações pascalianas no mérito da razão de ser e do ser social: a pesquisa de legitimidade para a própria existência particular, a conquista do direito de um indivíduo a sentir-se justificado para como ele existe. Uma razão de ser que move numa luta para não sucumbir a percepção da contingência da existência humana e ao pensamento da finitude, uma antropológica necessidade de estima e considerações sociais porque a "sociedade é Deus", capaz de dilacerar, isto é, com os seus atributos reconhecidos e a sua cogência simbólica, o indivíduo social ao risco da gratuidade da sua identidade e aquele da "insignificância de uma existência sem necessidade, estando entregue ao absurdo". (Meditazioni pascaliane. p. 248-251.)

BETTELHEIM, Bruno. La fortezza vuota. L'autismo infantile e la nascita del sé. Milano: Garzanti, 2001. p. 50.

ARENDT, Hannah. The Origins of Totalitarianism. New York: Medina, 1966. p. 300.

LYOTARD, Jean-François. The other's right. In: SHUTE, S.; HURLEY, S. (Org). On Human Rights - The Oxford Amnesty Lectures 1993. p. 146.

41 LYOTARD, Jean-François. The other's right. In: SHUTE, S.; HURLEY, S. (Org). On Human Rights - The Oxford Amnesty Lectures 1993. p. 147.

42 LYOTARD, Jean-François. The other's right. In: SHUTE, S.; HURLEY, S. (Org). On Human Rights - The Oxford Amnesty Lectures 1993. p. 427.

43 LYOTARD, Jean-François. The other's right. In: SHUTE, S.; HURLEY, S. (Org). On Human Rights - The Oxford Amnesty Lectures 1993. p. 427.

44 LYOTARD, Jean-François. The other's right. In: SHUTE, S.; HURLEY, S. (Org). On Human Rights - The Oxford Amnesty Lectures 1993. p. 427. Veja-se também SANTOS, Boaventura de Souza. If God were a Human Rights Activist: Human Rights and the Challenge of Political Theologies. In: Law Social Justice and Global Development, 1. Festschrift for Upendra Baxi, 2009.

\section{REFERÊNCIAS}

ARENDT, Hannah. The Origins of Totalitarianism. New York: Medina, 1966.

BENJAMIN, Walter. Sulla lingua in generale e sulla lingua dell'uomo. In: Angelus Novus. Saggi e frammenti. Torino: Einaudi, 1995.

BETTELHEIM, Bruno. La fortezza vuota. L'autismo infantile e la nascita del sé. Milano: Garzanti, 2001.

BORUTTI, Silvana. Wittgenstein impolitico? In: SPARTI, Davide (a cura di) Wittgenstein político. Milano: Feltrinelli, 2000.

BOURDIEU, Pierre. Il senso pratico. Roma: Armando Editore, 2005. . Meditazioni pascaliane. Milano: Feltrinelli, 1998.

BUTLER, Judith. Vite precarie. Violenza, lutto, politica. Roma: Meltemi, 2004. 
CASTEL, Robert. La Discrimination négative. Citoyens ou indigenes? Paris: Éditions du Seuil, 2007.

2008.

. La discriminazione negativa. Cittadini o indigeni?. Macerata: Quodlibet,

DAL LAGO, Alessandro. Esistono davvero i conflitti fra culture? n. 421, Bologna: ॥ Mulino, maio 2005.

GEERTZ, Clifford. The Interpretation of Culture. New York: Basic Books, 1973.

KOSELLECK, Reinhart. Futuro passato. Per una semantica dei tempi storici. Genova: Il Melangolo, 1986.

MARRAMAO, Giacomo. L'oltrepassamento della soglia dei desideri e la normatività della sofferenza. In: AA.VV. Nuove frontiere del diritto. Bari: Dedalo, 2001.

Passaggio ad Occidente. Filosofia e globalizzazione. Torino: Bollati Boringhieri, 2003.

MBEMBE, Achille. La République et l'impensé de la race. In: BLANCHARD, Pascal; BANCEL, Nicol; LEMAIRE, Sandrine. La Fracture coloniale. La société française au prisme de l'héritage colonial. Paris: La Découvert, 2005.

MUTUA, Makau. Savages, Victims, and Saviors: the Metaphor of Human Rights. In: Harvard International Law Journal. v. 42. Cambridge: Publications Center - Harvard Law School, 2001.

PERNIOLA, Mario. Transiti. Filosofia e perversione. Roma: Castelvecchi, 1998.

RORTY, Richard. Human Rights, Rationality, and Sentimentality. In: SHUTE, S.; HURLEY, S. (Org.). On Human Rights - The Oxford Amnesty Lectures 1993. New York: Basic Books, 1993.

SANTOS, Boaventura de Souza. A gramática do tempo: para uma Nova Cultura Política. Porto: Afrontamento, 2006.

Para além do Pensamento Abissal: das linhas globais a uma ecologia de saberes. In: Revista Crítica de Ciências Sociais. v. 78. Coimbra: Centro de Estudos Sociais da Universidade de Coimbra, 2007.

SPARTI, Davide. L'importanza di essere umani. Etica del riconoscimento. Milano: Feltrinelli, 2003.

- Oltre la politica del riconoscimento. Per una rilettura del nesso identità/riconoscimento a partire da Hannah Arendt e Stanley Cavell. In: Teoria Politica. n. 2. Milano: Franco Angeli, 2005.

STEINER, George. Dopo Babele. II linguaggio e la traduzione. Milano: Garanzi, 1994. 
STIEGLER, Bernard. Passare all'atto. Roma: Fazi, 2005.

WALLERSTEIN, Immanuel. The capitalist World-economy: Essay. Cambridge: Cambridge University Press, 1979.

WITTGENSTEIN, Ludwig. Lezioni e conversazioni sull'etica, l'estetica, la psicologia e la credenza religiosa. Milano: Adelphi, 1972.

YOUNG, Robert J. Introduzione al postcolonialismo. Roma: Meltemi, 2005. 2003. Postcolonialism. A very Short Introduction. Oxford: Oxford University Press,

Recebido para publicação: 16/09/2010

Aceito para publicação: 27/12/2010 